\title{
APPLICATION OF CLOUD TECHNOLOGIES IN ACCOUNTING
}

\author{
Liudmila Lapitkaia \\ ASEM, Department accounting, audit, and economic analysis, Chisinau, \\ Moldova \\ CMESTE \\ JEL Category: M41, M15
}

\begin{abstract}
Traditional accounting in modern conditions of digitalization of the economy requires significant changes in terms of the use of new information tools. One of these opportunities is the use of new information technologies in accounting. These new information technologies include cloud technologies, which are a specific environment (for storing, processing, and protecting information) that combines technical tools, software, communication channels, and technical support. Services that may be based on technology (MCloud) are a software as a service (SaaS), infrastructure as services (laaS), platform as services (PaaS). From the point of view of an accounting organization, the most convenient of these three types of services is the service as a software. Cloud technologies are the storage and processing of information on servers on the Internet. The positive aspects of using cloud technologies include the fact that accountants do not need to purchase, install the program on their computer, maintain it in working order, and ensure data protection and security. All this can be done in the cloud. Cloud storage - is online storage where information is stored on the network on servers provided by an information service provider for the use of customers. At the same time, cloud providers provide services for renting a server from various companies based on cloud technologies. The article analyzes the opportunities that cloud technologies provide in accounting, considers the advantages and disadvantages of using such technologies.
\end{abstract}

Keywords: MCloud, accounting, "cloud computing” technology.

\section{INTRODUCTION}

The recent rapid development of new technologies leads to the offer of various types of information services, improving the processing and storage of databases, and strengthening security measures against cyber threats.

The address of the author

Liudmila Lapițaia

䒠- liudmila1925@yandex.com
These new information technologies include cloud technologies, which are a specific environment (for storing, processing, and protecting information) that combines technical tools, software, communication channels, and technical support.

It should be noted that in the Republic of Moldova, based on article 2 of the Law on ratification of the Financial Agreement between the Republic of Moldova and the International Development Association, was published Government resolution No. 128 from 20.02.2014 on the 
establishment of the General government technology cloud platforms (MCloud).

This resolution defines "cloud computing technology ("information cloud") as an IT service delivery model that allows network access on request to a configurable set of computing resources subject to virtualization (for example, networks, servers, storage equipment, applications, and services) that can be quickly made available with minimal effort to administer them or interact with the provider of these services." (RM, 2014).

\section{ANALYSIS OF CLOUD SERVICES FOR ACCOUNTING}

Government resolution No. 128 specifies services that may be based on technology (MCloud), which are shown in figure 1.

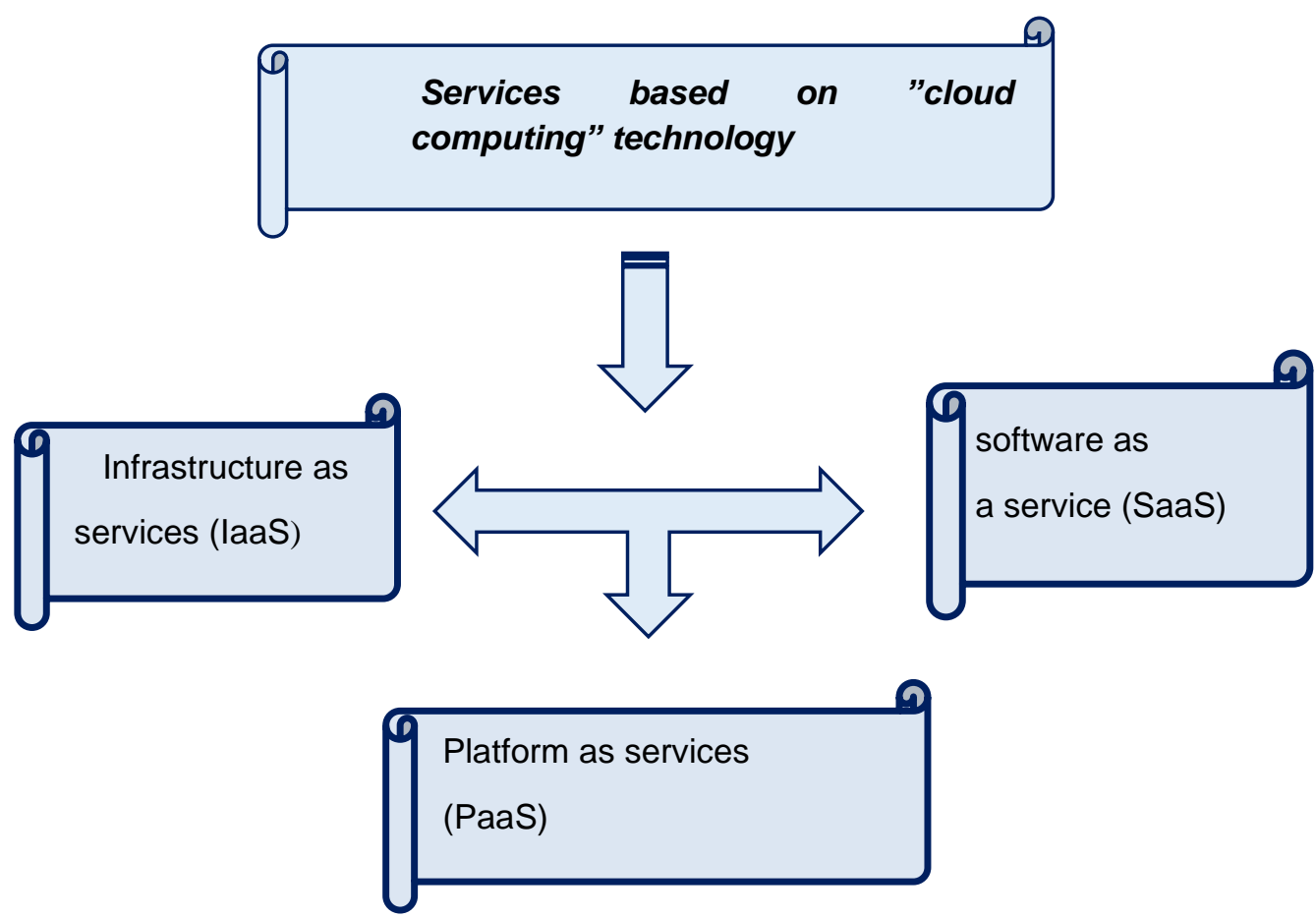

Fig. 1 Types of services based on "cloud computing" technology (RM, 2014)

Let us consider in more detail what these services are.

Infrastructure as a Service (laaS) is a model for the delivery of information services and resources, in which the supplier provides only the availability of resources requested by the client, and the rest of the work associated with the operation and administration of information systems is entrusted to the client:

- independently installs software required for the normal functioning of its licensed information systems located on the MCloud platform.

- provides, if necessary, the integration of own information systems located on the MCloud platform with other systems.

- administers its information systems located on the platform, including granting access rights to various components of information systems.

- provides security at the operating system level, protection of data processed within its own hosted information systems, as well as the creation and storage of backups on the MCloud platform (Laney, 2012).

Platform as a Service (PaaS) - a model for providing information services and resources, in which the client is provided with software components that they can use to implement their information services. In this model, the supplier provides the tools necessary for the operation and administration of the information solutions used by the client, and the responsibility for administration is assigned to the client. 
Table 1 Authority of the provider and recipient (client) of information services platform as a Service (PaaS)

\begin{tabular}{|c|c|}
\hline The & Recip \\
\hline $\begin{array}{l}\text { provides: } \\
\text { - availability, security, and access to the } \\
\text { requested platform software } \\
\text { components within the. } \\
\text { - if necessary, technical support for the } \\
\text { use and integration of platform } \\
\text { software components into information } \\
\text { systems hosted on the MCloud } \\
\text { platform. } \\
\text { - operating system licensing. } \\
\text { administers components of the platform } \\
\text { software. }\end{array}$ & $\begin{array}{l}\text { provides: } \\
\text { - integration platform software. } \\
\text { - components into their information. } \\
\text { - } \quad \text { systems. } \\
\text { - users of information systems hosted on the } \\
\text { MCloud platform, training and support. } \\
\text { - protection of data processed within our } \\
\text { information systems hosted on the MCloud } \\
\text { platform } \\
\text { manages its information systems hosted on the } \\
\text { MCloud platform, including providing access } \\
\text { rights to various components of information } \\
\text { systems; }\end{array}$ \\
\hline
\end{tabular}

Software as a Service (SaaS) as a model of information services and resources is their full provision. In this case, the service provider provides the components necessary for the operation and administration of the information solution, including data. In turn, the service recipients (clients) administer the received information services within their responsibility, manage access to the requested services for their administration.

From the point of view of an accounting organization, the most convenient of these three types of services is the service as a software. Cloud technologies are the storage and processing of information on servers on the Internet.

At the same time, information is processed and stored in the so-called cloud, which is a single large virtual server or servers that can be located remotely from each other.

Cloud servers have been long used, for example: when working with a client-Bank, when submitting reports, for example, tax in electronic form, when using email.

Recently, the range of information services for processing and storing accounting data in the cloud has been expanded. In this case, the cloud is a system that is a network of computers, software, and a platform on which data is stored, processed, and protected. However, the service of cloud technology providers can for money or free.
It should be noted that suppliers of automated accounting programs develop them with the ability to work via the Internet. Currently, the company "1C" has implemented cloud technologies in "1C: Enterprise accounting 8" version 3, or it can be called "cloud accounting 1C". Other Russian developers also have similar offers (infoEnterprise, Buchsoft, etc.).

The positive aspects of using cloud technologies include the fact that accountants do not need to purchase, install the program on their computer, maintain it in working order, and ensure data protection and security. All this can be done in the cloud.

Cloud storage - is online storage where information is stored on the network on servers provided by an information service provider for the use of customers. At the same time, cloud providers provide services for renting a server from various companies based on cloud technologies.

A company that provides a cloud service rents or hosts servers in a data center, which is a specialized secure building for hosting server and network equipment.

Information cloud providers, with license agreements with software vendors (1C, Microsoft), organize the infrastructure and offer fully configured workspaces with programs that customers can use over the Internet. 
The company that provides the cloud service supports the functionality of the infrastructure and provides technical and methodological support to users.

To ensure the safety of customer data, information service providers back it up, and copies can be uploaded to the user's local computer.

Accordingly, all accounting information is stored in the data center. At the same time, the clients do not need to purchase, install, or maintain their servers, they only pay for the use of the server for processing and storing data.

It should be noted that the company " $1 \mathrm{C}$ " has created its cloud service 1 cfresh, which is a single database with the separation of customer data. In this case, customers are given the opportunity to:

- connecting to the service not only via a web browser but also in the terminal client mode.

- ability to work with all the programs of "1C: Enterprise 8".

- ability to change the accounting program, add settings, i.e., access to the Configurator.

- ability to use integration with external programs and components.

For accounting purposes, the benefits of cloud technology can be considered, which are:

- the ability to use (rent) various programs without purchasing a license, since this function will relate to the service provider that will provide them to the client.

- using various software updates provided by information service providers, who will also be responsible for installing, configuring, and administering them.

- there is no need to purchase powerful servers, computers, or other hardware; the client pays only for the cloud storage space that they use, but not for renting a server that they may not use all of its resources.

- no need to purchase or maintain your data warehouse. All procedures for reserving and maintaining data integrity are performed by the cloud center provider.

- ease of implementation of various solutions: increasing or decreasing the number of users, connecting new external users (buyers or suppliers).

- the efficiency of entering data into the accounting program, since accountants can work from different places ( at home, at work, etc.).

The principle of working with "1C: Fresh" is similar to how a user usually works with e-mail or visits websites. It is enough to open any supported browser, enter the site address, personal login, and password it is possible to start working.

Using the functions of a personal account, it is possible to create the necessary database configurations, add and remove users. The databases themselves are stored on the $1 \mathrm{C}$ cloud server. In this case, the $1 \mathrm{C}$ company assumes all the costs of updating and storing the software complex.

The user can download a copy of the databases to his local computer. Thus, compatibility between all products of the 1C: Enterprise series is maintained.

Likewise, the local version of the database can be uploaded to the site and continue to work there already in the online service. All these operations can be performed very quickly and at virtually no cost.

A variant of joint mixed work in the database is possible using the program on a computer without access to the Internet or using a web browser. To do this, it is necessary to set up an offline workstation. Now, this is possible for the solution "1C: Accounting 8" version 3.0 (CIMA).

Autonomous workplace technology provides the following features:

- the user can work with the database both via the Internet and locally on their computer.

- to get started, it is necessary to set up an offline workplace once, and then update the configuration on the computer-based on the current version is available on the Internet.

- data in the offline workplace is always up to date. Synchronization in the service and on the local computer is performed either automatically on a schedule, or at the user's request.

Among providers of cloud technologies, it should be noted

- Netsuite,

- Xero,

- KashFlow,

- Zoho Books, 
- Intuit Quickbooks,

- FreeAgent,

- Sage 50c Premium,

- Wave,

- SAP Business One.

One of the advantages of cloud systems is the fact that the client is not geographically tied to the organization serving his accounting program, and therefore can choose the offer of any company that provides such services (Nathan Marz, 2015).

Developers of accounting software and service providers, in general, no longer need partners and representative offices in the regions - access to the cloud is possible from any point where there is an Internet connection.

At the same time, there are certain drawbacks in the use of cloud technologies, for example: linking the amount of payment for cloud services to the amount of data, many accountants prefer the form of payment for the database as a whole.

Also, a lot of questions arise in terms of security when storing and transferring data. When concluding contracts, service recipients are faced with the fact that material liability for data loss, unauthorized access, and distribution of data, at the suggestion of suppliers, often does not exceed the monthly cost of services, which is incomparable with the risks for customers.

However, the reliability and security of data storage and processing primarily depend on the Internet provider, cloud provider, data transmission channels, and the availability of the cloud at any given time.

In this regard, when concluding a contract with a cloud provider, it is necessary to pay attention to the following main points:

- technical characteristics of the service provided,

- $\quad$ information about the location of servers and responsibility for the temporary unavailability of the server,

- the obligation to create backup copies of the database, the obligation to save and restore information,

- obligations of the cloud service provider to maintain the confidentiality of user data, protect his data, including using cryptographic means, encryption,
- the consequences of termination of the contract and the timing of the removal of information belonging to the client,

- consequences of non-payment for services or poor-quality provision of services by the provider, number of fines.

In the contract with the cloud provider, the client must provide round-the-clock access to the cloud; daily backup and archiving of information databases (the storage period of each copy of the archive is at least 3 months); the client can access their backups for downloading to their computer (if necessary); encryption of communication channels; the ability to install updates to the accounting program immediately after its release without charging additional fees.

\section{CONCLUSIONS}

In conclusion, we would like to note that in the era of the digital economy, accounting specialists should study new information technologies, and in particular the possibility of their use in accounting. And first, the use of online accounting or internet accounting, which involves the organization of accounting using cloud technologies.

After analyzing the possibilities of online accounting, we can state that round-the-clock access to the accounting database is an advantage not only for accountants but also for business managers for control purposes.

Online accounting allows to coordinate the work of several remote offices, businesses, divisions, or employees optimally quickly in a single database. Also, online accounting will allow internal auditors to quickly monitor the reflection of business transactions in the system.

In the Republic of Moldova, the use of cloud technologies is still widespread only at the state level. However, some entrepreneurs in the field of information accounting technologies provide services with a cloud provider, however, the business does not require this service yet.

It would like to hope that the advantages of accounting when using cloud technologies will be appreciated by Moldovan accountants.

Based on global information trends, we can assume that the future of accounting is in cloudbased information technologies. 
The use of cloud technologies in accounting provides new opportunities for all business entities, regardless of their organizational and legal form and field of activity, including both budgetary institutions and non-profit organizations, and firms that provide outsourcing services in terms of accounting.

The main advantages of online accounting are wide availability, the flexibility of connected services, and an overall reduction in maintenance costs.

Every year, developers improve software technologies, and cloud technologies are on the list of trends in the development of information products for businesses. At the same time, there are four possible ways to use cloud technologies: cloud for working directly within the organization, cloud for holding, cloud for interacting with the client, and cloud technology for working over the Internet without installing software. With the help of cloud technologies, it is possible to implement all the traditional accounting tasks: keep electronic financial, managerial, tax records and compile statistical reports, generate primary accounting documentation, and perform calculations of taxes and insurance premiums.

\section{WORKS CITED}

CIMA. (n.d.). The effects of cloud technology on management accounting and decision making, Volume 10 - Issue 6. Retrieved from https://www.cimaglobal.com/Research--Insight/The-effects-ofcloud-technology-on-management-accounting/: $\quad$ https://www.cimaglobal.com/Research-Insight/The-effects-of-cloud-technology-on-management-accounting/

Laney, D. a. (2012, June 21). The Importance of 'Big Data': A Definition. Retrieved from https://www.gartner.com/: https://www.gartner.com/en/documents/2057415/the-importance-ofbig-data-a-definition

Nathan Marz, J. W. (2015). Big Data: Principles and Best Practices of Scalable Realtime Data Systems. Manning Publications.

RM, P. (2014, 2 20). Postanovleniye Nr. 128 ot 20.02.2014 ob obshchey pravitel'stvennoy tekhnologicheskoy platforme (MCloud). Retrieved from lex.justice.md: http://lex.justice.md/viewdoc.php?action=view\&view=doc\&id=351760\&lang=2

Received for publication: Revision received:

05.09.2020

Accepted for publication:
22.09.2020

30.12 .2020

\section{How to cite this article?}

Style - APA Sixth Edition:

Lapitkaia, L. (2021, January 15). Application of cloud technologies in accounting. (Z. Cekerevac, Ed.) MEST Journal, 9(1), 90-96. doi:10.12709/mest.09.09.01.12

Style - Chicago Sixteenth Edition:

Lapitkaia, Liudmila. 2021. "Application of cloud technologies in accounting." Edited by Zoran Cekerevac. MEST Journal (MESTE) 9 (1): 90-96. doi:10.12709/mest.09.09.01.12.

Style - GOST Name Sort:

Lapitkaia Liudmila Application of cloud technologies in accounting [Journal] // MEST Journal/ ed. Cekerevac Zoran. - Belgrade - Toronto : MESTE, January 15, 2021. - 1 : Vol. 9. - pp. 90-96. 
Style - Harvard Anglia:

Lapitkaia, L., 2021. Application of cloud technologies in accounting. MEST Journal, 15 January, 9(1), pp. 90-96.

Style - ISO 690 Numerical Reference:

Application of cloud technologies in accounting. Lapitkaia, Liudmila. [ed.] Zoran Cekerevac. 1, Belgrade - Toronto : MESTE, January 15, 2021, MEST Journal, Vol. 9, pp. 90-96. 